\title{
Nuclear proliferation and testing: A tale of two treaties
}

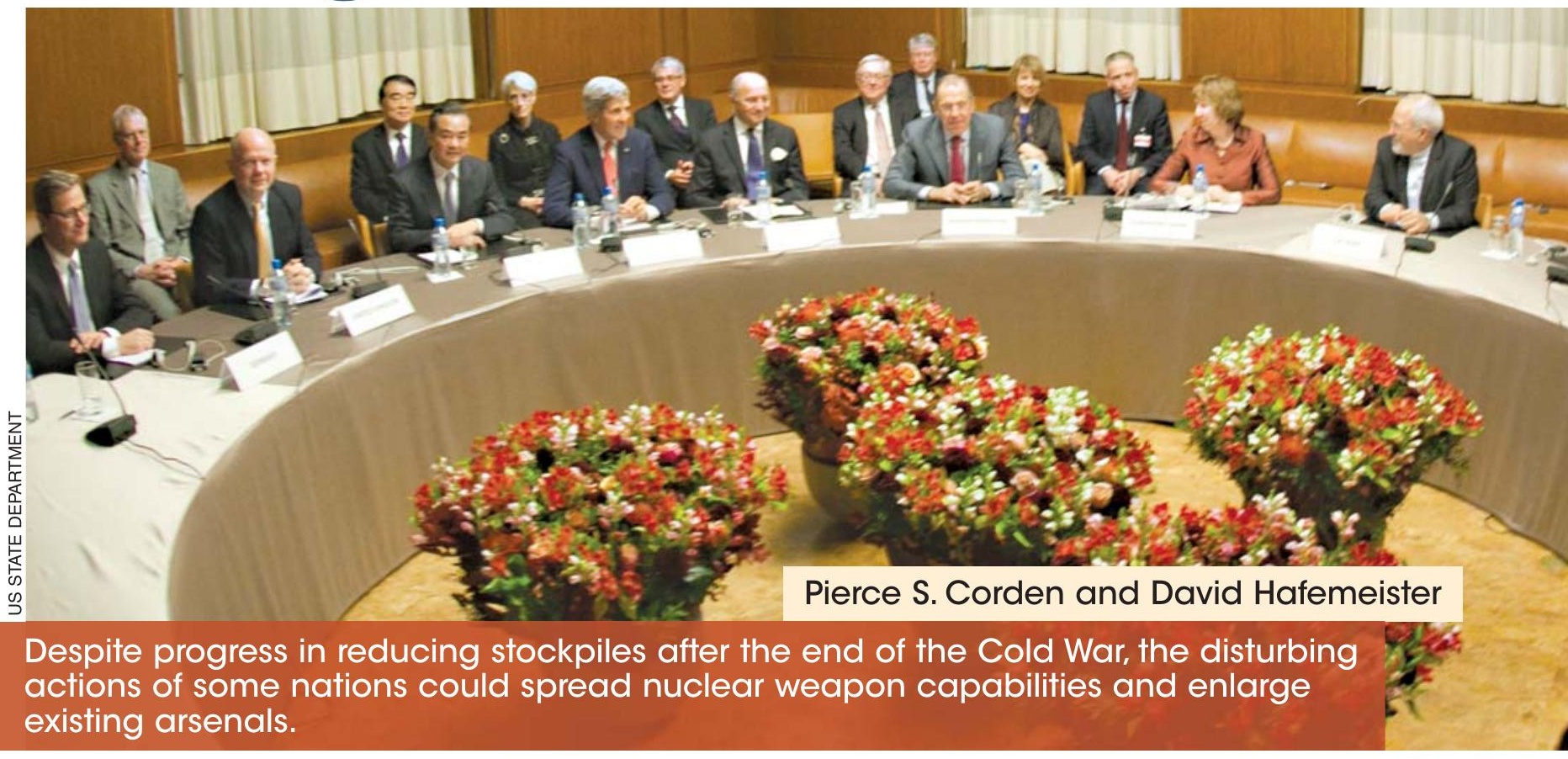

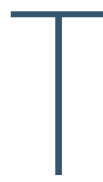

he first nuclear weapon explosion, codenamed Trinity, took place at Alamogordo, New Mexico, on 16 July 1945. Since then eight countries have carried out more than 2000 nuclear tests with yields from a fraction of a kiloton to some 50 megatons. (Yield is the amount of TNT needed for an equivalent explosion.) The public anxiety over nuclear testing began shortly after World War II, as the powerful but polluting atmospheric explosions exposed entire communities, known as downwinders, to the health hazards of radioactive fallout. Governmental anxiety followed in the late 1950s, and the US, USSR, and UK entered a moratorium on nuclear testing, only to have it fall apart three years later when the French began testing and the three countries resumed testing ever more powerful weapons with a vengeance.

In 1963, three years after President John F. Kennedy warned the public that as many as 20 countries might obtain nuclear capabilities by the end of the decade, the Limited Test Ban Treaty (LTBT) was negotiated to help curb the spread. That treaty prohibits testing in the atmosphere, under water, and in outer space, but not underground. Satellite surveillance and seismology were both very new at the time, and effective verification of a ban on underground explosions was widely thought impossible without onsite inspections, which were not part of the LTBT. Nonetheless, in 1968 the international commitment to comprehensively end nuclear testing was reaffirmed in another agreement, the $\mathrm{Nu}$ clear Non-Proliferation Treaty.
The NPT was built on a strategic bargain: The overwhelming majority of countries agreed to join the treaty as non-nuclear-weapon states, to not acquire nuclear weapons, and to allow inspections of their nuclear facilities. In return, the five nuclear weapon states - the US, UK, and USSR (now Russia), later joined by China and France and collectively known as the P5-pledged to work toward the elimination of their nuclear arsenals and to allow the sharing of peaceful nuclear technology with the non-nuclear-weapon states. ${ }^{1}$

At the time, the NPT signatories understood that the total elimination of all nuclear weapons was likely to be far in the future. Nearly half a century later, that's still the case. But India, Pakistan, Israel, and North Korea are not parties to the NPT, and dealing with their capabilities and those of the P5 proceeds in parallel with efforts involving the nonnuclear NPT parties. Figure 1 outlines the history of nuclear weapon proliferation since the first test in 1945. The US and USSR-Russia stockpiles have each declined by almost an order of magnitude from their peaks; the UK and French stockpiles have

Pierce Corden is a visiting scholar at the American Association for the Advancement of Science in Washington, DC, and previously led the State Department and US Arms Control and Disarmament Agency (ACDA) offices on the Comprehensive Nuclear-Test-Ban Treaty. David Hafemeister is an emeritus physics professor at California Polytechnic State University in San Luis Obispo and was formerly at the State Department, ACDA, and the National Academy of Sciences.

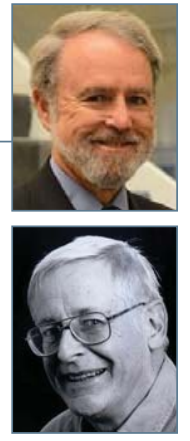


modestly declined. For others, either the picture is uncertain or the numbers are increasing.

If Iran were to build the bomb, in violation of its NPT obligations, how would NPT non-nuclearweapon states, such as Saudi Arabia and Egypt, react? If the US, China, or Russia were to resume nuclear testing, would that lead to testing by others and to new deployments of nuclear weapons? The NPT "regime" extends beyond the treaty in numerous ways to help counter those and other risks. Tools such as diplomacy between nations, arms control, economic sanctions, safeguards and protocols of the International Atomic Energy Agency (IAEA), physical security for nuclear materials and weapons, counterproliferation military strikes, port and border security, limits on the production of weaponsuseable uranium and plutonium, and the Proliferation Security Initiative-a global effort to stop trafficking in weapons of mass destruction - are all part of the broader regime. That interconnected system must be resilient to unpredictable changes. Further nuclear testing or withdrawal by a nation from the NPT would pose serious challenges to the regime.

In November 2013 two dozen experts spoke at a short course, cosponsored by the American Physical Society's Forum on Physics and Society and the George Washington University's Elliott School of International Affairs, to discuss those and other current threats to international security posed by nuclear weapons and related technologies. ${ }^{2}$ This article focuses on the NPT and national security - particularly as both are affected by the legal status of the closely linked Comprehensive Nuclear-Test-Ban Treaty (CTBT) and the ongoing developments in Iran and other nations.

\section{The NPT-CTBT intersection}

International law is not domestic law. Enforcement of international nonproliferation agreements includes measures decided by the UN Security Council. But those measures are effective only if most of the global community of nations adhere to them. Unfortunately, confidence in the NPT has been complicated by the fact that the CTBT, opened for signature in 1996, has yet to enter into force-that is, be ratified into law by China, Egypt, Iran, Israel, India, Pakistan, North Korea, and the US. (See the article by Jeremiah Sullivan, PHYSICS TODAY, March 1998, page 24.)

The holdouts are troubling. For one thing, there is broad international support for the CTBT: The treaty has been signed by 183 states, has been ratified by 162 , and bans nuclear tests at any yield, at any place, and for all time. For another, during negotiations to secure a permanent extension of the NPT, France, Russia, the UK, and the US sent a letter, dated 19 April 1995 (China later agreed), to the NPT Review and Extension Conference promising a CTBT: ${ }^{1}$

We reaffirm our determination to continue to negotiate intensively, as a high priority, a universal and multilaterally and effectively verifiable comprehensive nuclear test-ban treaty, and we

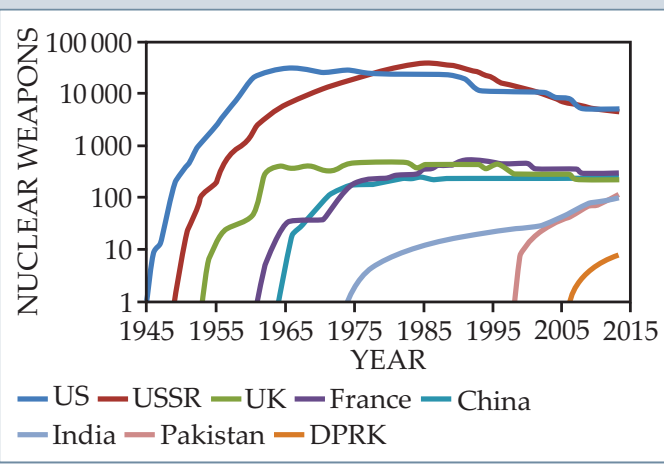

Figure 1. Nuclear weapons, counted. The approximate number of stockpiled weapons in each country is keyed to the date of its first nuclear test. (Adapted from data of Hans Kristensen, http://www.fas.org.) The following are 2013 totals: US, 4650 stockpiled, 2120 operational; Russia, 4300 stockpiled, 1600 operational; UK, 225; France, 300; China, 250; India, 90-110; Pakistan, 100-120; and North Korea (DPRK), 5-10.

pledge our support for its conclusion without delay.... We call upon all States parties to the [NPT] to make the treaty provisions permanent. This will be crucial for the full realization of the goals set out in Article VI.

In 1999, when the US Senate considered giving its advice and consent to ratification, it declined to do so. In the hearings and floor debate, the verifiability of the treaty and the effectiveness of the US nuclear weapons stockpile in the absence of nuclear-explosive testing were principal issues cited as problematic. The contention caused by the failure of the US and the other seven states to ratify the CTBT does not help develop the global consensus needed to enforce nonproliferation undertakings. Without the CTBT, the NPT is perceived as a treaty of unbalanced obligations.

A ban on nuclear tests is a nonproliferation and arms-control measure that raises the barrier for states to move toward nuclear weapons and blocks existing nuclear powers from substantial new technical advances. Although such a barrier would not prevent the development of simple gun-type weapons, which typically do not require testing to work, it prevents development of thermonuclear weapons and the miniaturization of nuclear weapons for missiles. ${ }^{3}$

At the 2010 NPT Review Conference, all 189 NPT members viewed the CTBT's entry into force as essential for a strengthened nonproliferation regime. In December 2013 the United Nations General Assembly urged all nations to sign and ratify the CTBT on a vote of 181 yes, 1 no (North Korea), and 3 abstentions (India, Mauritius, Syria). The Obama administration has declared its support for Senate action to ratify the treaty.

\section{Seismic monitoring}

Since 1963, when the LTBT was adopted, the capabilities of seismology to detect underground nuclear explosions have steadily improved. By the time the CTBT was negotiated at the Geneva Conference on 


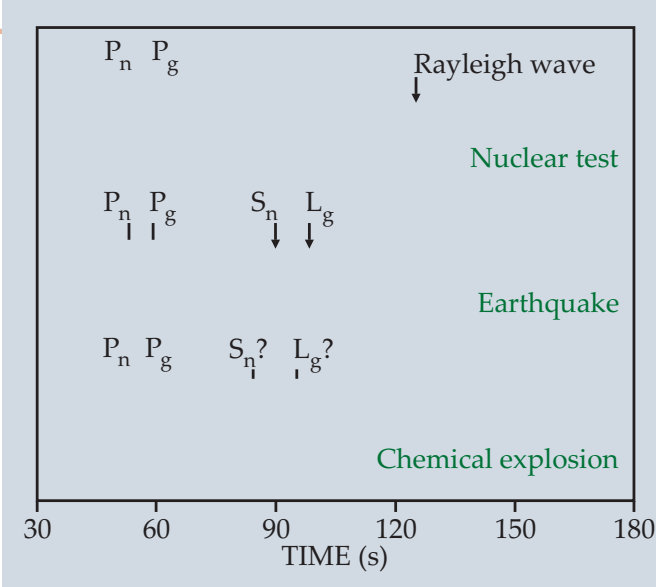

Figure 2. Seismic spectrographs taken in Mudanjiang, China, record the ground-velocity amplitudes of three events a few hundred kilometers away in North Korea: a 9 October 2006 nuclear test (top) of magnitude 4 ( $0.7 \mathrm{kt}$ equivalent yield); a 16 December 2004 magnitude 4 earthquake (middle); and a 19 August 1998 underground chemical explosion (bottom; 0.002 kt equivalent yield). The nuclear and chemical explosions cause the sudden onset of compressive waves that travel either through the crust and mantle $\left(P_{n}\right)$ or through the crust alone $\left(P_{g}\right)$ and the later onset of weak shear waves $\left(S_{n}\right.$ and $\left.L_{q}\right)$ and Rayleigh waves, a type of surface wave. Compressive waves in earthquakes emerge more slowly and their shear waves are stronger than in the explosions; indeed, the shear waves are so weak in both nuclear and chemical explosions that labelling their emergence in spectra is difficult. (Adapted from ref. 11.)
Disarmament in the mid 1990s, seismic instrumentation had matured so dramatically that it and other test-detection technologies provided a very effective means to verify states' compliance with the new treaty.

The CTBT establishes the International Monitoring System (IMS), networks comprising 321 seismic, radionuclide, hydroacoustic, and infrasound sensors around the world $-84 \%$ of them certified, $5 \%$ installed, $6 \%$ in construction, and $5 \%$ planned. Thanks to the relatively high density of the 170-station seismic network, states have access to a richer set of data than was possible when the LTBT was negotiated, when there was no regular access to territories of states of interest, particularly the USSR. The seismic network can detect explosions at more reduced yield levels than previously. "National technical means" - the nationally owned and operated seismic and other sensors, reconnaissance satellites, ships, and aircraft - provide an additional and powerful source of verification that exceeds the capability of the IMS networks.

Regional and long-range seismic waves are used to distinguish between explosions and earthquakes, estimate the magnitude of an event, and determine its location so that follow-up onsite inspections can be carried out in ambiguous cases. Consider figure 2, which compares seismograms from a low-magnitude earthquake, a chemical explosion, and the 9 October 2006 nuclear explosion in North Korea. The nuclear test was detected widely by the IMS and other stations in South Korea, China, and Japan. A later North Korean nuclear explosion, on 12 February 2013, was detected by 96 IMS stations, which were able to locate the test site to within $8 \mathrm{~km}$.

Regional waves predominantly travel through Earth's crust and upper mantle and are strongly affected by local geology, which can complicate interpretation, but they offer better, more detailed results than long-range waves. In 2001 seismologists Vitaly Khalturin, Tanya Rautian, and Paul Richards analyzed the regional signals collected between 1961 and 1989 at distances 500-1500 km from underground explosions at the former Soviet test site at Semipalatinsk in Kazakhstan. Usefully detailed seismic information was found in the old Soviet data from all but two of 340 tests with yields over a ton. ${ }^{4}$

Newer broadband seismographs are suffi- ciently sensitive that, according to a 2002 National Academy of Sciences (NAS) study, ${ }^{5}$ underground nuclear explosions conducted in hard rock anywhere in Europe, Asia, North Africa, and North America can be reliably detected and identified as explosions down to a yield of $0.1 \mathrm{kt}$ using IMS data. The denser the seismic network in a particular region, the greater the detection probability. A 2012 National Research Council (NRC) report has mapped the magnitudes and yields that a nuclear test anywhere in the world would have to exceed in order to be detected. ${ }^{6}$ As shown in figure 3 , explosions well below a kiloton can be detected with $90 \%$ confidence.

The probability that a state seeking to violate the CTBT can repeatedly evade detection drops rapidly with an increased number of tests. Additionally, geophysicists Ola Dahlman, Svein Mykkeltveit, and Hein Haak point out ${ }^{7}$ that the violator would have to reduce its test explosion's yield by a factor of three to reduce the seismic detection probability from $90 \%$ to $10 \%$. Further compounding the risk of being detected, violators must take into account the synergy provided by other IMS networks, possible onsite inspections, possible excess yields, and information available from the thousands of seismic stations operated by academic and disaster-preparedness organizations to monitor earthquakes.

One evasion scenario, envisioned in the 1950s, is "cavity decoupling" - the use of a cave or underground cavity intended to muffle the seismic waves from a nuclear explosion and thus reduce the radiated signal. Even in that case, according to the 2012 NRC report, "an evasive tester in Asia, Europe, North Africa, or North America would need to restrict device yield to levels below 1 kiloton (even if the explosion were fully decoupled) to ensure no more than a 10 percent probability of detection for IMS and open monitoring networks" (page 10). ${ }^{6}$ And that doesn't account for the deterrent provided by states' national technical means and from the IMS network of radionuclide sensors.

\section{Iran's centrifuges}

To build a nuclear weapon, one must first produce the fissile material that powers it. Historically, the most common path to that end was to extract plutonium from the spent fuel rods of heavy-water reactors that used natural uranium. That method was India's path to its 1974 test explosion. A less common 
approach was to enrich uranium to increase the abundance of its fissile isotope ${ }^{235} \mathrm{U}$. Uranium enrichment was difficult with bulky gaseous diffusion technology, and active diplomacy convinced several nations in the 1970s to abandon plans for reprocessing spent fuel.

Thirty years later, centrifuge technology has advanced sufficiently that it is now the chosen path for acquiring highly enriched, bomb-grade uranium. Because gas centrifuges require much less power and space than reactors and reprocessing plants, they are much easier to hide. And their growing use represents a challenge: how to prevent the development of nuclear weapons and still allow the peaceful use of nuclear energy. Both goals are part of the NPT. (See the article by Houston Wood, Alexander Glaser, and Scott Kemp, PHYSICS TODAY, September 2008, page 40.)

The enrichment of uranium is measured in separative work units (SWUs) and is a nonlinear process. A common light water reactor (LWR) producing about a gigawatt of electric power consumes each year approximately 25 tons of $3.75 \%$-enriched fuel, obtained from 210 tons of natural uranium, and requires 120000 SWU. Figure 4 offers an example of the extent to which the separative work diminishes as uranium is enriched from its natural form of $0.7 \%$

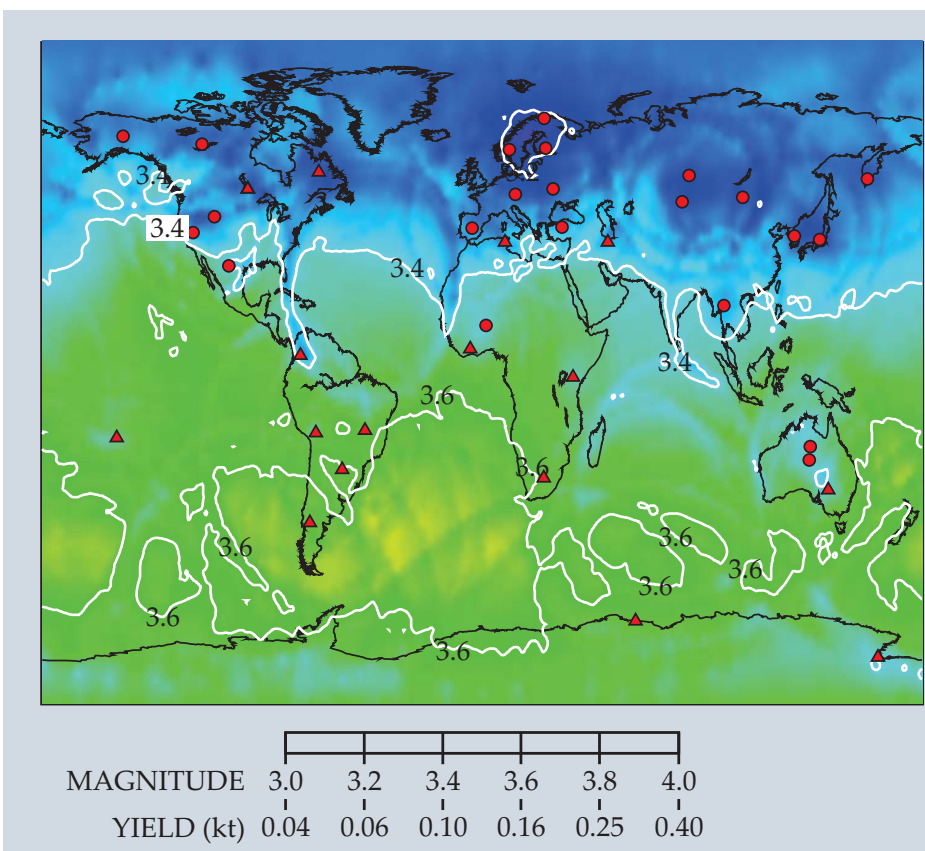

Figure 3. The detection capability of the International Monitoring System's seismic network is correlated to the magnitude of Earth's seismic events. In 2007, when this map was made, the primary network consisted of 38 stations (dots and triangles) around the world. The map's colors correlate the minimum seismic magnitude to the explosive yield in kilotons in hard rock required for $90 \%$-confidence-level detection. For example, one can be $90 \%$ sure of detecting any tests above $0.09 \mathrm{kt}$ in Asia, Europe, and North Africa for tamped explosions in hard rock with better propagation, and $0.22 \mathrm{kt}$ in rock with poorer propagation. If the confidence level is relaxed to $10 \%$ detection, the yields are reduced by a factor of three. (Adapted from ref. 6, courtesy of Tormod Kvaerna and Frode Ringdal.)
${ }^{235} \mathrm{U}$, to its highly $(90 \%)$ enriched form. It requires about 800 SWU per ton of uranium to make $130 \mathrm{~kg}$ of $4 \%$-enriched reactor fuel. An additional 300 SWU yields $26 \mathrm{~kg}$ of $20 \%$ highly enriched uranium, and a further 200 SWU yields $5.6 \mathrm{~kg}$ of $90 \%$ HEU. Put another way, it takes about $60 \%$ of the total work to produce low-enriched LWR fuel, $25 \%$ of the total to enrich the fuel to $20 \%$, and another $15 \%$ of the total to raise that amount to $90 \%$. Thus, a stockpile of $20 \%$ enriched material can significantly reduce the time a country requires to make a nuclear weapon.

Argentina, Brazil, China, France, Germany, India, Iran, Japan, the Netherlands, North Korea, Pakistan, Russia, the UK, and the US currently enrich uranium. Commercially enriched stock is primarily supplied by Europe's URENCO (10 million SWU/year), Russia's Rosatom (26 million), and France's AREVA (10 million). Iran's centrifuges produce $0.8-4$ SWU/year, ${ }^{8}$ and the country has claimed the right to pursue uranium enrichment in line with the NPT. But its claim has been a subject of dispute, considering that Iran had not reported its past enrichment activities to the IAEA. The developments have prompted condemnation in UN Security Council resolutions. Other nonweapon states that enrich uranium have negotiated acceptable reporting and inspection agreements with the IAEA.

Figure 5 shows the growing numbers of centrifuges Iran has installed and is operating at its large facility in Natanz since 2007. (To date, Natanz and the other main centrifuge facility, at Fordow, together house 19000 centrifuges.)

\section{P5 plus 1}

An agreement known as the Joint Plan of Action between Iran and the P5 (plus Germany) took effect on 20 January 2014. In the agreement, which will last six months, Iran allows constraints to be placed on its nuclear program in exchange for a reduction of $\$ 7$ billion in economic sanctions. The agreement approximately doubles the "breakout time" needed to obtain sufficient HEU to build a nuclear weapon; the IAEA counts $25 \mathrm{~kg}$ of $90 \% \mathrm{HEU}$ as a "significant quantity," sufficient for a weapon.

According to the plan, ${ }^{9}$ Iran agrees to halt uranium enrichment above $5 \%$ and cap the production of $3.5 \%$-enriched uranium; dilute or oxidize the country's near-20\%-enriched stock; stop the installation of additional centrifuges at Natanz, Fordow, and elsewhere; freeze advances at the country's heavy-water reactor in Arak; allow monthly verification inspections of the reactor and daily inspections of the Natanz and Fordow facilities; provide access to centrifuges, production facilities, uranium mines, and mills; and notify the IAEA in a timely manner about any new nuclear facilities.

The primary goal of the constraints is to maintain at least a six-month breakout time so that the UN can respond well before Iran can make sufficient weapons-grade uranium if the country reneges on the agreement. Detection of the production of uranium enriched over $5 \%$ would be a violation of the joint agreement. David Albright, president of the nonprofit Institute for Science and International Security, and colleagues calculate a breakout time of 
six months if Iran kept $150 \mathrm{~kg}$ of $20 \%$-enriched material and $2000 \mathrm{IR}-1$ centrifuges, $250 \mathrm{~kg}$ of $20 \%$-enriched material and 1000 centrifuges, or no amount of $20 \%$ enriched material and 6000 centrifuges. ${ }^{10}$

An inspection regime can weigh and examine cylinders containing feed, product, and wastes to determine enrichment levels. Radio-frequency identification tags can track the cylinders. Similarly, tags, seals, and surveillance can be used to keep track of nuclear activity. Uranium stocks, records, and receipts can be audited. Environmental samples of soil and water can be obtained in and outside a plant. Unannounced inspections are useful to detect undeclared material and operations.

The IAEA and the US have had considerable experience in nuclear monitoring. The technology used to monitor the "blend-down" of 500 tons of Russian HEU to reactor fuel is instructive. The density of ${ }^{235} \mathrm{U}$ in the uranium hexafluoride gas can be determined by measuring the emission of $186-\mathrm{keV}$ gamma rays from the uranium. And the transmission of $122-\mathrm{keV}$ gamma rays from cobalt- 57 through the $\mathrm{UF}_{6}$ gas determines total uranium density. The ratio of the two values yields the enrichment level. Twenty years of monitoring by Oak Ridge and Los Alamos (LANL) National Laboratories have verified the dilution of Russian HEU in the equivalent of 20000 HEU warheads.

\section{Confidence in untested nuclear weapons}

The enduring US stockpile consists of several types of warheads; they include tactical and strategic bombs and land- and submarine-launched ballistic missiles. The US has not tested any of them since 1992. The directors of LANL, Lawrence Livermore (LLNL), and Sandia National Laboratories have concluded that nuclear-explosive testing is not needed to resolve technical issues concerning the US nuclear stockpile.

At the November 2013 short course, ${ }^{2}$ Texas A\&M University's Marvin Adams surveyed the US Stockpile Stewardship Program and agreed with a central conclusion from the NRC's 2012 report (reference 6 , page 1 ):

Provided that sufficient resources and a national commitment to stockpile stewardship are in place, the committee judges that the United States has the technical capabilities to maintain a safe, secure, and reliable stockpile of nuclear weapons into the foreseeable future without nuclear-explosion testing.... Sustaining those technical capabilities will require ....

- a strong science and engineering base... ;

- a vigorous surveillance program;

- adequate ratio of performance margins to uncertainties;

- modernized production facilities; and

- a competent and capable work force.

Stockpile stewardship assesses the status of warheads, including the impact of changes made to them, and takes any needed actions to maintain near certainty that weapons would meet require-

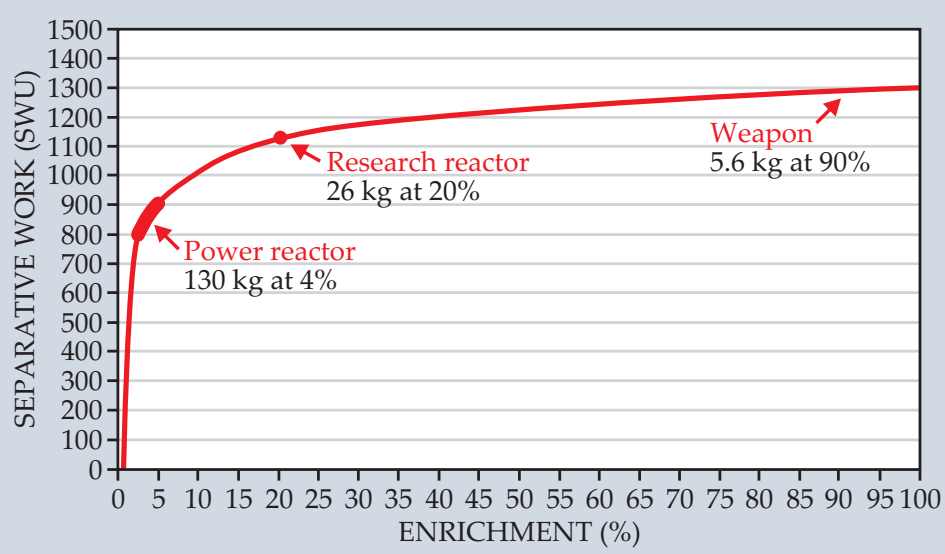

Figure 4. The effort required to enrich uranium and increase the concentration of its fissile isotope ${ }^{235} \mathrm{U}$ diminishes exponentially as the concentration rises. The effort is measured in separative work units. Starting with 1 ton of natural uranium, it takes 800 SWU to produce $4 \%$-enriched reactor fuel, an additional $300 \mathrm{SWU}$ to produce $20 \%$-enriched material for research reactors, and 200 more SWU to produce $90 \%$-enriched material. (Courtesy of Olli Heinonen.)

ments if used. (See the article by Raymond Jeanloz, PHYSICS TODAY, December 2000, page 44.) That assessment, in practice, translates into monitoring the warheads, repairing any observed degradation, dismantling retired warheads (now about 250 per year), and extending the life of the remaining stockpiled weapons.

Scientists at LANL and LLNL have determined a lower limit of 85 to 100 years for the lifetime of a plutonium "pit," the part associated with the fission stage of a nuclear explosive. The JASONs, a group of technical experts who advise the Defense Department, agreed with that assessment. One may simply reuse the plutonium-based pit when a weapon's life is extended. However, long-term stockpile stewardship requires the ability to manufacture new pits. Currently the Los Alamos Pit Production Facility fulfills that role and can produce $6-10$ pits per year; further investment could boost its production to as many as 80 pits per year.

Modifications in the warheads are being considered to enhance their safety, security, and performance margins as part of upcoming life-extension programs (LEPs); see PHYSICS TODAY, December 2013, page 26. According to Adams, the actions being considered in LEPs can include refurbishing existing warheads, reusing the nuclear components from different warheads, and replacing nuclear components with designs not previously in the stockpile. All LEPs require some manufacturing, and any change in a weapon requires the assessment of experts familiar with the latest advances in experiments, theory, and computation. Opportunities to introduce changes are relatively rare because LEPs are carried out on a multidecade time scale.

The following points summarize developments in stockpile stewardship since the NAS's 2002 CTBT study was carried out:

- LEPs are a reality, successfully carried out for land- and submarine-based warheads.

- Peta-scale computation is now available to aid design, stewardship, and understanding of a weapon's behavior. 


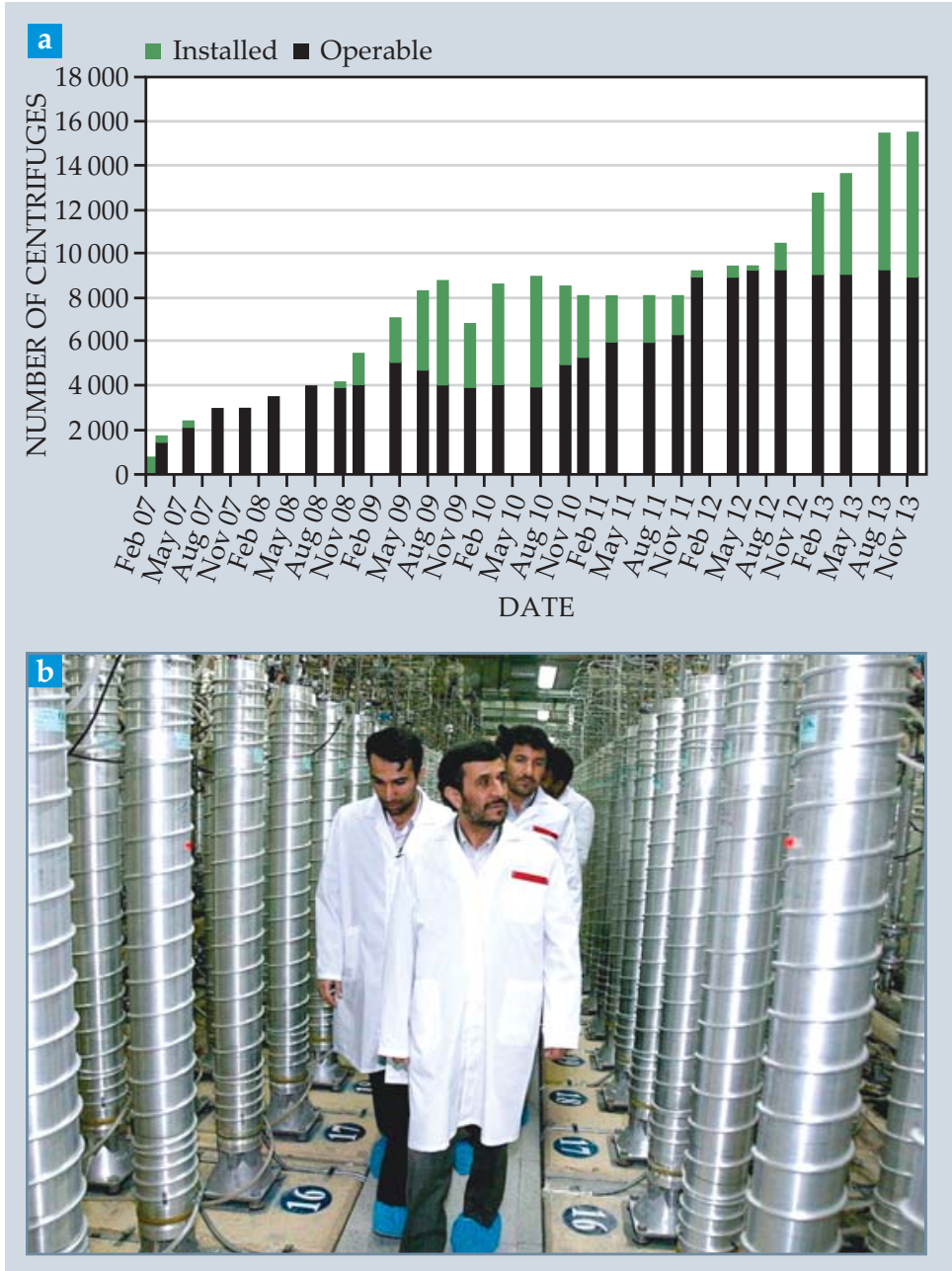

Figure 5. The number of Iran's centrifuges at Natanz (a) in 2013 grew to nearly 16000 , a roughly $60 \%$ increase from the previous year. Combined with the number at a smaller facility in Fordow, the country currently has a total of 19000 centrifuges. Operable centrifuges (black) are enriching uranium hexafluoride. Inoperable centrifuges (green) include installed machines not yet fed with $\mathrm{UF}_{6}$ and a large fraction damaged by sabotage in 2009 and 2010 when the computer virus Stuxnet infected the operating system. The plateau in late 2013 may be related to the negotiations between Iran and the P5-plus-1 (the US, UK, Russia, China, France, and Germany). (Plot courtesy of David Albright.) (b) Then-president Mahmoud Ahmadinejad inspects the Natanz nuclear plant on 8 March 2007. (Photo courtesy of EPA/Landov.)

- The National Ignition Facility and Dual-Axis Radiographic Hydrodynamic Test Facility have been completed for studying relevant physics.

- The future of the Chemistry and Metallurgy Research Replacement Facility at LANL and the Uranium Production Facility at the Department of Energy's Y-12 National Security Complex at Oak Ridge are in doubt because of cost.

Although the NAS and NRC panels concluded that the US can maintain a reliable stockpile without nuclear-explosive testing, the stewardship program's future success isn't guaranteed. The biggest concern is the ability to attract, develop, and retain a first-class work force. Adams urges several steps:
Professionals in the US should be involved with related nonproliferation, counterterrorism, and science issues to maintain their expertise and skills. The weapons labs should continue to maintain first-rate facilities, some for unclassified work. Experts outside the weapons facilities can provide helpful assessments, as it is difficult to assess quality "from the inside." The gaps in understanding of weapons' behavior can be addressed with ongoing experiment, theory, simulation, and analysis of past data.

\section{Final thoughts}

There's a highly compelling reason the US and other nuclear-weapon-possessing states don't test nuclear weapons: To do so would not only invite a new arms race, it would make addressing the nuclear programs in Iran and North Korea much harder and put the nonproliferation regime at risk.

India and Pakistan are examples of what happens in the absence of an arms-control agreement. Both countries have roughly the same nuclear capability and are continuing to build larger and more sophisticated arsenals. International efforts to deal with their competition have not led to a halt, let alone a reversal. A 2006 agreement between India and the US gives India more flexibility on nuclear imports. And the US war in Afghanistan loosened international pressure on Pakistan's nuclear programs. One can hope that at least for the near term, the development of confidence- and securitybuilding measures will give diplomacy time to prevent a nuclear crisis.

\section{References}

1. T. Graham Jr, D. Hafemeister, Disarmament Diplomacy 91, 16 (2009).

2. P. Corden, D. Hafemeister, P. Zimmerman, eds., Nuclear Weapons Issues in the 21st Century, AIP Publishing, Melville, NY (in press).

3. For a description of the technical objectives of testing, see P. Corden, in CTBT at 15: Status and Prospects, Arms Control Association, Washington, DC (October 2012), p. 10; P. S. Corden, Phys. Soc. 42 (2), 11 (2013).

4. V. Khalturin, T. Rautian, P. Richards, Pure Appl. Geophys. 158, 143 (2001).

5. National Academy of Sciences, Committee on Technical Issues Related to Ratification of the Comprehensive Nuclear Test Ban Treaty, Technical Issues Related to the Comprehensive Nuclear Test Ban Treaty, National Academies Press, Washington, DC (2002).

6. National Research Council, Committee on Reviewing and Updating Technical Issues Related to the Comprehensive Nuclear Test Ban Treaty, The Comprehensive Nuclear Test Ban Treaty: Technical Issues for the United States, National Academies Press, Washington, DC (2012).

7. O. Dahlman, S. Mykkeltveit, H. Haak, Nuclear Test Ban: Converting Political Visions to Reality, Springer, Dordrecht, the Netherlands (2009), p. 167.

8. D. Hafemeister, Physics of Societal Issues: Calculations on National Security, Environment, and Energy, 2nd ed., Springer, New York (2014), p. 167.

9. D. Albright, in ref. 2; Department of State, Background Briefing on the Implementation Plan of the P5+1 and Iran's First Step Nuclear Agreement, 13 January 2014, http: //www.state.gov/r/pa/prs/ps/2014/01/219571.htm.

10. D. Albright et al., Maintaining at Least a Six-Month Breakout Timeline: Further Reducing Iran's Near 20 Percent Stock of LEU, http://isis-online.org.

11. P. Richards, W.-Y. Kim, Nat. Phys. 3, 4 (2007). 